\title{
Introduction to the Special Issue on Sexuality in the Caribbean
}

\author{
Karen Carpenter
}

Published online: 8 October 2011

(C) Springer Science+Business Media, LLC 2011

The Caribbean Sexuality Research Group (CSRG) is indeed proud to have been given the opportunity of contributing to this special issue of Sexuality \& Culture. The CSRG is a non-profit, non-discriminatory working group that recognises diversity in orientation, language and ethnicity throughout the region and focuses on research into sexualities in the Caribbean and its diaspora. The group is comprised of professionals from a wide variety of areas related to human sexuality. The articles in this issue of Sexuality \& Culture reflect a small part of that diversity, as seven of our twenty-five members have been included in here.

In their article, Cowell and Saunders explore the challenge of legal reform as it relates to the public discourse around heteronormativitiy and homosexuality. In Wine, Women and Song, Hubert Devonish examines the explicit sexual expression of Caribbean women in dance and the challenging of male dominance through these public displays. Carpenter and Walters, in A So Di Ting Set, take the reader through a decade of musical expression in Barbados and Jamaica comparing these with the current sex role stereotypes of men and women emerging from both countries. In Goodbye to Flesh, Anna Perkins looks at the fleshy images of Carnival in Trinidad against the backdrop of a tradition of Christian repression of the body's desires. Christopher Charles closes this issue with his article on skin bleaching among dark skinned women driven by the perception that lighter skinned women or "brownings" are the sexual ideal.

Each of these articles exposes a particular aspect of Caribbean culture that is integral to sexual expression, sexual identity and sexual desire. In the Caribbean, music plays a vital role in informing and reflecting the everyday experience of its people. It is impossible to go across any of the islands on a given day without hearing music played in public and private spaces. As expressions of this musicality,

K. Carpenter $(\bowtie)$

Department of Language, Linguistics and Philosophy, University of the West Indies, Mona,

Kingston 7, Jamaica, West Indies

e-mail: karen.carpenter@uwimona.edu.jm 
Carnival, Crop Over and Festival allow the masses a public outlet and celebration after months of hard work. These celebrations are largely gaudy and noisy displays of drinking, music and revelry, which fly in the face of traditional "good behavior". In fact, patrons are openly encouraged to "get on bad" or "behave badly" in the lyrics of the songs and the mood of the festivals. All of this takes place in a context where the legal systems of these small island states continue to struggle with the sanctioning of same sex relations and the valuing of behavior outside of the heteronormativity that is currently supported by the laws of the islands.

This special issue of Sexuality \& Culture on Caribbean sexuality opens a small window on some of the practices of a region that has influenced the world through its export of music, sports, and cuisine. The Caribbean Diaspora has made its indelible mark culturally from Notting Hill Carnival in London to Reggae festivals in Soweto and Japan. The CSRG, through the articles contained here, provides a further glimpse into issues facing the region and beyond. We hope that Sexuality \& Culture readers enjoy the articles. 